\title{
GUERRA, ESTADO Y ORGANIZACIÓN SOCIAL DE LA PRODUCCIÓN. LA CORONA DE ARAGÓN EN GUERRA CON CASTILLA, 1429-14301
}

\author{
Luis Pablo Martínez Sanmartín \\ Universidad de Valencia
}

\begin{abstract}
SUMARIO
1. Prolegómenos de la guerra. La primera incursión en Castilla (junio de 1429).- 2. La segunda incursión del Magnánimo, exponente de diferencias estructurales entre Castilla y la Corona de Aragón (agosto-septiembre de 1429).- 3. El mercado de las armas: una oferta insuficiente para una demanda perentoria.- 4. Intervención estatal en la producción de armamento, guerra de 1429-1430.
\end{abstract}

\section{Prolegómenos de la guerra: la primera incursión en Castilla (JUNIO DE 1429).}

Alfonso V el Magnánimo, rey de Aragón, llevó a cabo en el transcurso del verano de 1429 dos entradas en Castilla de muy distinto signo. La primera, emprendida el 23 de junio, pretendía ser un deslumbrante paseo militar enmarcado en una operación de chantaje político. Durante los meses previos a la expedición, sus preocupaciones en cuanto a lo que podrí-

'Comunicación presentada al "XV Congreso de Historia de la Corona de Aragón" (Jaca, 20-25 de septiembre de 1993). Este trabajo se inscribe en el marco de mi proyecto de investigación Tecnología, desarrollo y estructura social en una formación feudal de frontera: el reino de Valencia, ss. XIII-XV, subvencionado por la Conselleria de Cultura, Educació i Ciència de la Generalitat Valenciana mediante la concesión de una beca de F.P.I. Quisiera expresar mi agradecimiento a Antoni Furió y José Sanmartín, directores del mismo, y a mi compañero Jorge Sáiz Serrano, con quien he compartido fatigas y sudores peleando largo tiempo con la contabilidad de la tesorería general de la Corona de Aragón. A continuación incluyo la relación de abreviaturas empleadas: Arxiu del Regne de València (ARV), Arxiu Municipal de València (AMV), Biblioteca del Real Colegio-Seminario del Corpus Christi de València (BCCV), Arxiu de la Corona d'Aragó (ACA), sous (ss.), diners (d.). 
amos calificar como "gastos de intendencia" atendían únicamente a la compra y fabricación de accesorios de lujo, más que propiamente de suministros bélicos: para él mismo, diversos arneses y tiendas de campaña, y para sus acompañantes (entre $2.0(0)$ y $3.0(0)$ caballeros y unos $1.0(0)$ peones) $)^{2}$, todo un fastuoso vestuario. Ataviados con al menos novecientas quince chaquetas «de drap blanch, cascuna de quatre Sitis Perillosos, que són de drap de grana perfilats de fil d'or e d'argent e de sedes de diversitats de colors" " ${ }^{3}$ y adornados con mil cuatrocientas plumas de avestruz ${ }^{4}$, el séquito real tenía poco que ver con un ejército en campaña y mucho con un desfile de gala. Sus integrantes marchaban «tanto a punto, que más parescen divinos que humanos"'. La ineptitud de sus hermanos, los infantes Enrique, maestre de Santiago, y Juan, rey de Navarra, le había obligado finalmente a presentarse en persona en Castilla para restaurar el poder y el buen nombre de su linaje, "a gran honor e glòria del dit senyor e de la reyal Corona d'Aragó" ${ }^{6}$. Apareciendo en el escenario castellano como el deslumbrante

Según Zurita el séquito constaría de unos 2.000 caballeros (cfr. Jerónimo Zurita, Anales de la Corona de Aragón, Zaragoza, 1974, 5a parte, libro 13, cap. 53, p. 700). La crónica de Juan II da unas cifras de 2.500 caballeros y 1.000 peones (cfr. Crónica de Juan II, en "Biblioteca de Autores Españoles», LXVIII, Madrid, 1953, p. 457, col. a), y según la crónica de Álvaro de Luna serían 3.000 caballeros y 1.000 peones (ifr. Juan de Mata Carriazo (ed.), Crónica de don Alvaro de Luna, condestable de Castilla, maestre de Santiago, Madrid, 1940, cap. 19, p. 76). Las discrepancias podrían obedecer la contabilización conjunta o no del contingente navarro.

' ARV, Mestre Racional, 8.774, f. 119 v.; Joan de Bonastre, "cambrer, deputat a tenir la guardaroba [del rey]" se encargó de la fabricación de 486 chaquetas (ARV, Mestre Racional, 8.778, f. 68 r.-v.); Conti del Castell, "brodador de casa del senyor rey", de 100 (ARV, Mestre Racional, 8.774, f. 162 r.), y el baile general del reino de Valencia, Joan Mercader, de otras 329 (ARV, Mestre Racional, 9.823 (3), ff. 27 v.-28 v.). La tesorería general registra, además, un enorme gasto para la confección de "certes robes de livrea blanques e vermelles, les quals $[\ldots]$ foren dades $[\ldots]$ als munters, fills de cavallers, sots oficials e ajudants, porters, trompetés, ministrers e altres officials e domèstichs de casa sua" (por un importe de 12.223 ss. 6 d. de Barcelona: A.R.V., Mestre Racional, 8.774, f. 160 v.), diversos “jaqs d'armar" para miembros distinguidos de la casa real, etc.

4 ARV, Mestre Racional, 9.823 (3), f. 25 r. y 26 r.-v.

5 Texto de una carta de los reyes de Aragón interceptada por los castellanos, según el cronista de Álvaro de Luna (Crónica de don Álvaro de Luna, cit., cap. 19, p. 76).

${ }^{6}$ Carta escrita por Eiximén Pérez de Corella, gobernador del reino de Valencia y brazo derecho del rey en asuntos militares, el 1 de julio de 1429. Ferrando de Torquemada, correo, recibió una recompensa de 20 florines "per albíxeres e estrenes d'aquell de la bona e sancta nova que ha portada als honorables jurats de la dita ciutat de València [...] donant sobiran e gran goig e alegria als dits honorables jurats / com per aquella han sabut e són estats certificats com lo molt alt e virtuós senyor rey nostre ha obtengut tot ço que volia, e per què era anat en Castella, a gran honor e glòria del dit senyor e de la reyal Corona d'Aragón: AMV, Claveria Comuna, 0-12, f. 111 r.-v. 
campeón de la casa Trastámara, este monarca "predestinado" que escogió de forma significativa la silla peligrosa de la leyenda artúrica como divisa?, confiaba sin lugar a dudas que su mera presencia, acompañado por una importante fuerza disuasoria ${ }^{8}$, provocaría un levantamiento automático de la nobleza castellana contra el advenedizo Álvaro de I.una. Por ello concibió su entrada de forma tan espectacular, invirtiendo en seda en lugar de acero.

De hecho, sus preocupaciones militares se orientaban en dirección opuesta, hacia Italia. Ello viene refrendado por el estudio de la contabilidad de la tesoreria general de la Corona de Aragón entre enero y mayo de 1429, período en el cual la inversión en material bélico remite a la construcción naval, apuntando claramente hacia Nápoles: fabricación en Barcelona de ciento sesenta remos y velamen completo para dos galeras de nueva factura custodiadas en Cullera9, y apertura de un camino en las montañas de Vic para facilitar el transporte con carros ${ }^{10}$ de la madera allí cortada hacia las atarazanas barcelonesas (marzo de 1429), todo ello estimado en 8.230 ss. $8 \mathrm{~d}$. de Barcelona ${ }^{11}$. A 7 de marzo el rey escribía desde Zaragoza al lloctinent de batlle general del reino de Valencia, Francesc Torres, comunicándole que tenía "gran plaer [...] de l'apuntament e de l'adreç de la nostra galera [...] e de la bona cura que havets e donats contínuament acerca de les artelleries e altres coses per nós a vós comanades» ${ }^{12}$. Francesc Torres había gastado en el transcurso del año

"La SEDIA COL FUOCO è ricordata nei documenti o nelle cronache col nome di "sitio peligroso, siti perillós, silla fogosa, sedice perigliosa, segia de foco, segia col foco». La troviamo sola, oppure accanto all'altra impresa del libro aperto, nei primi codici fatti per Alfonso. Il De Osma pensa che essa dovette essere suggerita al re dal romanzo di Thomas Malory "La morte d'Arthur", dove si racconta di una sedia che alla tavola rotonda rimaneva sempre vuota e aveva il nome di "siese perillous» perchè Merlino aveva detto che chi ci si fosse seduto sarebbe morto, eccetto un uomo solo, il predestinato»: Tammaro DE MARINIS, La biblioteca napoletana dei re d'A ragona, I, Milán, 1952, p. 131.

8 Según Zurita, «deliberó llevar consigo alguna gente de armas no en gran número, para refrenar la osadía y atrevimiento de los que intentasen de procurar y mover algunos escándalos contra el rey de Navarra y contra el infante don Enrique, entre tanto que estuviesen en la corte del rey de Castilla»: Anales, cit., $5^{\text {a }}$ parte, libro 13, cap. 52, p. 699.

9 ARV, Mestre Racional, 8.774, f. 136 v. y 170 v.

10 «Ítem, doné a.n Johan Çafont, de mon offici [...] mil florins en direcció d'un camí novament construïdor de manament del senyor rey de les montanyes de Cabrera entro al Mas appellat vulgarment de l'Esquirol, construïts en los monts de Osona, per ço que lo passatge sia pus àbil per los carros ab què s'ha a traure fusta del dit bosch tallada e apparellada e apparelladora, axí per los rems de les galeres com en altra manera»: ARV, Mestre Racional, 8.774, f. 77 r.

11 Las cantidades vendrán habitualmente expresadas en moneda de cuenta valenciana, en sous reials de València. Únicamente consignaré la procedencia cuando no se trate de moneda valenciana, como en el presente caso. En todos los demas, me limitaré a poner las cantidades en sous y diners, tratándose siempre, insisto, de moneda de cuenta valenciana.

12 ARV, Real Cancillería, 232, f. 259 v. 
anterior $68.2(0)$ ss. "en la ciutat de València, en alcunes artelleries e altres coses que fa fer " ${ }^{14}$, mientras que en Barcelona un oficial de la tesorería, Joan Çafont, supervisaba la fabricación del velamen y encargaba la confección de gran número de corazas y astas de proyectil de ballesta ${ }^{14}$, actividades que forman parte de una inversión en preparativos navales (incluyendo soldada de naves, subvenciones para su construción, etc.) próxima a los 35().(0)(0) ss.

En 1425, y en circunstancias bastante más complicadas, un movimiento de tropas a lo largo de la frontera bastó para que Castilla se plegara a sus directrices. ¿Por qué ahora no iba a ser así? El plan, sin embargo, se vino abajo ante la pasividad demostrada por la nobleza castellana afín y, sobre todo, por una decidida toma de la iniciativa por parte del condestable Álvaro de Luna ${ }^{15}$. La aventura concluía con una declaración formal de guerra por parte de Castilla que precipitó los acontecimientos.

\section{La SEgUnda inCURSIÓN Del MaGNÁNIMO, EXPONENTE DE DIFEREN- Cias estructurales entre Castilla y la Corona de Aragón (AGOSTO-SEPTIEMBRE DE 1429)}

A la declaración de guerra castellana del 29 de junio siguió un amago de batalla en territorio castellano los días 1 y 2 de julio ${ }^{16}$, la retirada de los

13 ARV, Mestre Racional, 8.772 , f. 150 v.; 8.773 , ff. 141 v. y 168 v.

14 ARV, Mestre Racional, 8.773, f. 71 v.; Real Cancilleria, 232, doc. cit.

is Alan RYDER, en el capítulo "Preocupaciones castellanas (1424-1432)» de su obra Alfonso el Magnánimo. Rey de Aragón, Nápoles y Sicilia (Valencia, 1993, pp. 151-220) realiza una brillante exposición de los hechos, haciendo ver que el rey es llevado a inmiscuirse en la política castellana en contra de sus intereses, y fundamentalmente por la torpeza de sus hermanos Enrique y Juan, cuyos recelos mutuos contribuyeron a la ruina de la rama Antequera de los Trastámara en Castilla tanto o más que las intrigas de Álvaro de Luna. Aún contando con precedentes de la talla de Jaume VICENS VIVES, que en el punto "La política castellana i la intromissió de Catalunya en els afers reials" de su conocida obra Els Trastàmares (Barcelona, 1961, pp. 118-122) ofrece una magnífica síntesis de las líneas maestras de la política de aquel tiempo, el estudio de Ryder se halla mucho mejor documentado.

${ }^{16}$ Dada su inferioridad numérica, Álvaro de Luna se fortificó en su campamento, ubicado sobre una loma cerca de Cogolludo (Guadalajara), mientras que el ejército navarroaragonés se desplegaba en orden de combate. La mediación del legado pontificio, cardenal de Foix, y de la reina María de Aragón evitó la refriega, contra el parecer de Juan de Navarra y en favor de los intereses del rey Alfonso, que retrasó la declaración de guerra a Castilla hasta que los acontecimientos le hicieron ver la irreversibilidad de la conflagración. A 23 de julio, casi un mes después de la ruptura oficial de hostilidades por parte castellana, escribía desde Calatayud de su puño y letra a su secretario Francisco d'Arinyo, que estaba en Valencia "e d'oy me faga ese reyno gerra, entrando en Castilla tan crua e áspera como podrán, guardando las Yglesias»: BCCV, Fondo Mayans, 677, f. 203 v.. 
reyes de Aragón y Navarra a Calatayud, una cabalgada en Aragón del condestable de Castilla y una ofensiva castellana en toda regla iniciada el 4 de agosto, esta vez encabezada por el propio rey Juan $\mathrm{II}^{1}{ }^{1}$. Todo ello motivó un incremento febril de la actividad de la burocracia estatal aragonesa. El objetivo: obtener dinero fresco y en cantidad suficiente como para mantener en pie el ejército (renovación de soldadas ${ }^{18}$ ), y la reunión de los pertrechos necesarios para resistir la ofensiva castellana y, si cabía, contraatacar. El inmediato desarrollo de los acontecimientos demuestra que tales objetivos se cubrieron con creces. Los castellanos, pese a reunir un número considerable de efectivos ${ }^{19}$, fracasaron reiteradamente ante aquellas plazas fuertes que en lugar de dárseles «a partido» (mediante pacto) decidían plantar cara. Por la fuerza de las armas sólo lograron tomar «algunos pequeños lugares del Reyno de Aragón» ${ }^{20}$. Y lo que es más significativo, la gran ofensiva conjunta de las tropas del rey Juan II y de su condestable quedó abortada nada más comenzar. Ambos emprendieron, desde su campamento ubicado en la localidad castellana de Santa María de Huerta (sobre la misma frontera de Aragón), la vía de Calatayud, donde se albergaban los reyes de Aragón y de Navarra. Pero el castillo de Ariza, defendido por unos doscientos hombres de armas aragoneses, se convirtió en un obstáculo insalvable para los inva-

17 Ese día estableció su campamento ante el castillo de Ariza: no pasaría de allí. $C f r$. Jerónimo Zurita, Anales, cit., $5^{2}$ parte, libro 13, cap. 54, p. 706.

it Como establece Jorge SÁrz Serrano, Estado y poder militar en la Corona de Aragón: el ejéritito del rey en la guerra con Castilla (1429-1430), comunicación presentada al «XV Congreso de Historia de la Corona de Aragón" (Jaca, 20-25 de septiembre de 1993). Los preparativos militares contra Castilla fueron posibles merced a la concesión de un cuantioso crédito de 50.000 florines, librado al contado por los consellers de la ciudad de Barcelona al tesorero Francesc Sarçola mediante dos dites en la Taula de Canvis de dicha ciudad. La operación financiera fue fulgurante, como la subsiguiente reacción militar aragonesa: firmado el contrato el día 3 de agosto, el día 4 el tesorero percibía ya una dita por valor de 132.000 ss. barceloneses, y el resto le era liquidado mediante otra dita de $418.000 \mathrm{ss}$. el día 12 del mismo mes (ARV, Mestre Racional, 8.777, ff. 8 r.-9 v.), datos que expuse en compañía de Jorge Sáiz Serrano en nuestro trabajo Actividad militar y crecimiento del Estado: la financiación de la guerra en la Corona de Aragón y el reino de Valencia (1416-1431), comunicación presentada al citado "XV Congreso de Historia de la Corona de Aragón».

19 «Serían esta gente que con el Rey entró más de diez mil hombres darmas, e ginetes e peones sesenta mil e más, según paresció por los alardes que se hicieron»: Crónica de Juan II, cit., p. 464, col. a. Aunque la cifra parece hinchada, no cabe duda de que el rey castellano iría bien acompañado, porque según el cronista el «llamamiento general de todos los hijosdalgo" tuvo tanto éxito que Juan II hubo de licenciar a parte de los llegados al campamento antes de iniciar la ofensiva: "a este real llegó tanta gente [...] que no abastaban viandas, ni eran menester tan gran muchedumbre de gentes, e por eso el rey mandó que todos los que eran venidos por el llamamiento general se fuesen para sus tierras, salvo algunos de Vizcaya e Asturias que mandó que quedasen" (ibid., p. 461, col. b).

${ }^{20}$ Crónica de Juan II, cit., p. 464, col. a. 
sores $^{21}$. Su decidida resistencia paralizó la ofensiva castellana cuando sólo había penetrado unos diez kms. en territorio aragonés. Poco tiempo antes, los mil quinientos integrantes de la cabalgada de Álvaro de Luna fueron incapaces de tomar una simple casa fuerte nobiliar que se les resistió en Cetina ${ }^{22}$. La crónica de Pero Niño, caballero castellano que participó en los acontecimientos, nos dice que se trataba de "una muy fuerte casa, y bien enderezada, la iual no se podía tomar sin pertrechos, y por luengo tiempo" ${ }^{23}$, coincidiendo con el cronista de Juan II, quien, tras indicar que uel lugar [la villa] se tomó por la fuerza de las armas", señala que «no se tomó la fortaleza, que es asaz buena de calicanto e bien torreada" ${ }^{24}$. Todo parece indicar, pues, que los castellanos se hallaban faltos de "las cosas necesarias para salir en campo y combatir algunas fuerzas", definición que da Zurita ${ }^{25}$ del vocablo medieval artillerías. La crónica de Álvaro de Luna refuerza esta impresión cuando, entre las diversas razones que el condestable esgrime ante el rey Juan II para que levante el cerco de Ariza y regrese a Castilla, afirma que "para se echar sobre alguna çibdad, o villa, o fortaleza, no tenía el rey los pertrechos que eran neçesarios, nin los podría haver en breven, ${ }^{26}$. Del mismo modo, la crónica de Juan II señala que los miembros del real consejo recomendaron al monarca castellano "volver en su reyno [...] e aparejar todo lo necesario para el año venidero entrar en los reynos de Aragón, así con pertrechos e artillerías para combatir, como con fornimiento de muchas viandas" ${ }^{27}$.

${ }^{21}$ Alan Ryder se equivoca al afirmar que "el rey de Castilla [...] asedió el castillo de Ariza, que se rindió al cabo de tres días» (Alfonso el Magnánimo, cit., p. 205). En Ariza, como en Cetina, los castellanos sólo pudieron tomar la villa (el espacio urbanizado, siempre menos defendible), no la fortaleza. De ser así, la vía de Calatayud (salvo la empalizada de Ateca) hubiese quedado expedita, y la guerra hubiera transcurrido por otros derroteros más desfavorables a los aragoneses.

${ }^{22}$ Las tropas del Condestable "destruyeron la vega de Cetina", pero "aunque se entró el lugar por combate (que era de un caballero de los de Calatayud de los Liñán que se decía Gonzalo de Liñán) tenía una casa por el edificio fuerte y era de piedra y bien torreada y por el asiento della llana; y defendióse de suerte que no se pudo entrar por combaten: Jerónimo Zurita, Anales, cit., $5^{2}$ parte, libro 13, cap. 54, p. 706. El cronista de Álvaro de Luna indica que se trataba de "una casa fuerte [...] ca era de piedra bien torreada, como quiera que era llana por assentamiento", y excusa que el condestable no la pudiese tomar "por la grand acucia que el condestable ovo de volver al rey, por entrar con él en Aragón»: Crónica de don Alvaro de Luna, cit., cap. 23, p. 91.

${ }^{23}$ Gutierre Díaz De Games, El Victorial. Crónica de don Pero Niño, Madrid, 1989, p. 291 (el subrayado es mío).

${ }^{24}$ Crónica de Juan II, cit., p. 464, col. a.

25 Jerónimo Zurita, Anales cit, $5^{\text {a }}$ parte, libro 11, cap. 16, p. 330.

${ }_{26}$ Crónica de don Alvaro de Luna, cit., cap. 24, p. 95 (el subrayado es mío).

${ }^{27}$ Crónica de Juan II, cit., p. 464, col. b. 
El hecho es que, levantado el cerco, el rey de Castilla necesitó prácticamente todo un año para preparar una ofensiva en condiciones. Sin embargo, Alfonso el Magnánimo únicamente precisó un mes para contraatacar con contundencia en territorio castellano: entre agosto y septiembre de 1429, consolidó el frente de Calatayud mediante la toma por la fuerza de los castillos de Cihuela, Deza, Ciria, Serón, Beratón y Borobia, y la capitulación del de Vozmediano ${ }^{28}$ (vid. fig. 1). El único castillo que lograron conquistar los castellanos durante sus incursiones de julio fue el de Monreal de Ariza, $y$ se les dio mediante pacto ${ }^{24}$. Los aragoneses, por su parte, tomaron seis castillos por la fuerza de las armas, y sólo uno mediante pacto, en una campaña relámpago de unos doce días (blitzkrieg bajomedieval) entre el 27 de agosto, toma de Deza ${ }^{30}$, y el 9 de septiembre, fecha en la cual el rey está ya de regreso en Aragón ${ }^{31}$. El vigor y la presteza del contraataque aragonés impactó sin lugar a dudas en la opinión castellana. Así, las palabras que el cronista de Juan II dedica a narrar "cómo el rey de Aragón entró en Castilla e tomó por la fuerza la villa e castillo de Deza e los castillos de Ciria e Borovia, y el castillo de Bozmediano que le fue vendido por el alcayde», destilan una enojosa admiración. Según él, Alfonso $V$ "certificado que la villa de Deza estaba a mal recabdo [...] trasnochó desde Calatayud con hasta mil hombres de armas e dos mil peones, e mandó llevar escalas e otros pertrechos para combatir. E tan sin sospecha llegó en amanesciendo a la villa, que ante que los vecinos della se pudiesen ayudar de las armas, la villa fue tomada. Y el castillo se combatió de tal manera que el mesmo día se tomón" ${ }^{32}$. Cuando el rey de Aragón se presentó ante el castillo de Vozmediano, la última escala de su contundente ofensiva, es lógico que su alcaide entablase negociaciones de inmediato ${ }^{33}$. Juan II de Castilla asistió impotente, desde

28 Jerónimo Zurita, Anales, cit., 5 parte, libro 13, cap. 55, p. 708; Crónica de Juan II, cit., p. 467, col. a.; ARV, Mestre Racional, 8.777, f. 103 v.

29 Jerónimo Zurita, Anales, cit., 5 a parte, libro 13, cap. 54, p. 705.

30 Alan Ryder señala que «en la noche del 26 de agosto [Alfonso V] salió de Calatayud, cubrió cuarenta y cinco kilómetros de terreno áspero y se presentó al día siguiente y sin previo aviso ante la ciudad fronteriza castellana de Deza. Su artillería de inmediato martilleó los muros hasta tal punto que tanto la ciudad como el castillo cayeron al primer asalto y sufrieron un exhaustivo saqueo" (Alfonso el Magnánimo, cit., pp. 205-206). Efectivamente, Deza cayó en 27 de agosto, según afirma el rey en carta fechada el 29 de agosto «dada en lo nostre camp reyal de Deça»: ARV, Gobernación, 4.255, f. 167 r.-v.

${ }^{31}$ Fecha de una orden de pago librada por un escrivà de ració dada en el «camp reyal de Novalles [Novallas, cerca de la frontera con Navarra] del regne de Aragón: ARV, Mestre Racional, 8.777, f. 100 v.

32 Crónica de Juan II, cit., p. 467, col. a (el subrayado es mío).

${ }_{33}$ Tras tomar Deza, el ejército partió «llevando captivos todos los moradores así christianos como moros; y metieron la villa a sacomano, e quemaron e derribaron algunas casas[...] e tomó asímesmo los castillos de Ciria e Borovia, e mandó soltar todos los christia- 


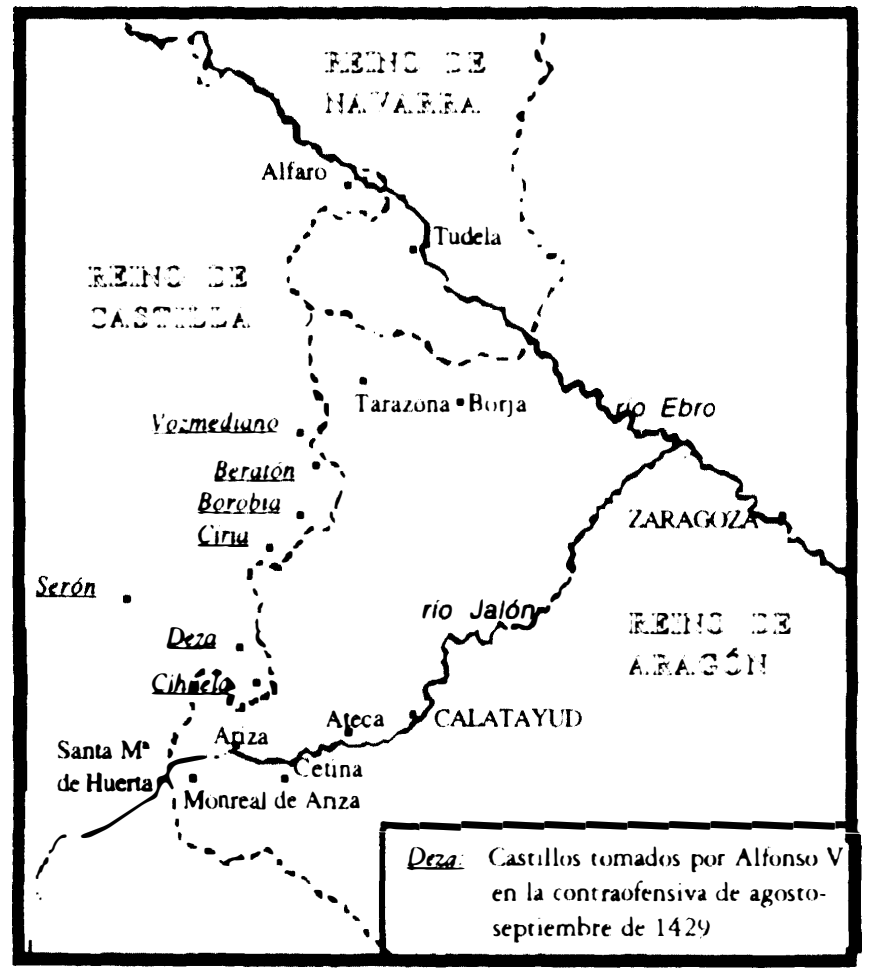

Fig. 1. Guerra con Castilla de 1429-1430: teatro principal de operaciones

Peñafiel, al desarrollo de los acontecimientos, «de que hubo grande enojo...n ${ }^{34}$.

La intendencia jugó un papel determinante en la rapidez y el éxito de la contraofensiva: el ejército aragonés, unos mil cuatrocientos caballeros y dos mil peones ${ }^{35}$, se apoyaba en una recua de doscientas veinticinco mulas y veintiocho carros "portants diverses coses e artillaries del dit senyor; e anaren a Techa, e de Techa e Calataiú, al siti de Deça del regne de Castella, e a altres lochs de Castella, e aprés són tornats ab les dites artellarias a la dita ciutat de Calataiú " ${ }^{36}$, mientras otro convoy de ciento cuarenta y tres acémilas abastecía los castillos de la frontera y, finalmente, se unía al cuerpo prin-

nos que había llevados presos de Deza con que no se volviesen a ella; y llevó consigo todos los moros. E llegó a Serón, e anduvo por algunos otros lugares de tierra de Soria haciendo mucho mal e daño; e créese que llevó más de diez mil cargas de trigo y cevada, e muchos muebles e ganados de los vecinos de aquella tierra" (Crónica de Juan II, cit., p. 467, col. a). Es lógico, pues, que el alcaide de Vozmediano capitulase ante la llegada del poliorcéticamente muy eficiente ejército aragonés, aunque el cronista castellano se limite a denunciar su «maldad", porque, según él, "gelo vendió por dineros» (ibid.).

34 "...especialmente porque se hizo engañosamente» (Crónica de Juan II, cit., p. 467, col. a). Engañosamente porque Juan II había enviado requerimientos oficiales de batalla en campo abierto a los reyes de Aragón y de Navarra. Se consideraba traicionado de acuerdo a la ética caballeresca.

35 Jerónimo Zurita, Anales, cit., $5^{\text {a }}$ parte, libro 13, cap. 57, p. 721.

36 ARV, Mestre Racional, 8.777 , ff. 103 v.y 89 r. 
cipal de ejército que, habiendo vuelto a penetrar en Aragón tras la captura de Vozmediano, planeaba un ataque a la localidad castellana de Alfaro a través de territorio navarro ${ }^{37}$. El propio Álvaro de Luna reconoció que uno de los mayores peligros que amenazaba a las tropas castellanas estancadas en el cerco de Ariza, radicaba en la actividad de la intendencia aragonesa. Los reyes de Aragón y de Navarra estaban haciendo un acopio manifiesto de recursos en su refugio de Calatayud ${ }^{38}$, mientras los castellanos se desgastaban en un inútil asedio. Sometidos a idénticas presiones, la diferente capacidad de reacción de los antagonistas resulta, pues, muy reveladora: el conflicto de 1429-1430 refleja una situación típica donde a la fuerza y la cantidad (Castilla) se opone un uso eficiente de los recursos (Corona de Aragón).

\section{El MERCADO DE LAS ARMAS: UNA OFERTA INSUFICIENTE PARA UNA DEMANDA PERENTORIA.}

Para contrarrestar el tremendo hándicap geopolítico y material que para la Corona de Aragón suponía un enfrentamiento con Castilla y obtener, a su vez, una ventaja relativa tan ostensible como la que los hechos ponen de manifiesto, la monarquía y sus órganos de gestión hubieron de realizar una meticulosa planificación de la guerra capaz de llevar a las sociedades que integraban sus dominios a rendir más allá de los estándares habituales. Esto resulta particularmente evidente por lo que respecta al ámbito de la producción de armamentos. Si bien en otras actividades, como en la movilización de recursos financieros para sufragar los costes de la campaña, la monarquía se benefició enormemente del recurso a una infraestructura

37 «CXXXXIII bèsties de bast qui són estades preses e meses en loguer delà departídement en la ciutat de Calataiú, // les quals portaren en los mesos de agost e de setembre propasat vituales, armes e altres coses per forniment dels castells d'Aragó qui estan en la frontera de Castella, e encara aportaren en lo dit temps armes, artellaries e altres coses necessàries al combat que.l dit senyor devia donar [a] Alfaro": ARV, Mestre Racional, 8.777, f. 114 v. Por su parte, el tesorero habla en sus cuentas de "lo camí per mí fet en lo dit mes de setembre de la vila de Borja al loch de Alfaro, del regne de Castella, anant ab lo senyor rey acompanyat de gent d'armes»: ibid., f. $131 \mathrm{v}$. Alfaro, una cuña de territorio castellano en Navarra, amenazaba la ciudad de Tudela y el corredor del Ebro (vía fundamental para la penetración hacia la capital aragonesa), fue el fracaso que cerró la billante contraofensiva del Magnánimo. Pero ello no obedeció a fallos logísticos, como podemos apreciar, sino a la declaración de una epidemia entre los caballos del ejército aragonés (cfr. Alan RYDER, Alfonso cit., p. 206).

38 «E pues los reyes estaban tan çerca de Ariza, e avía tantos días que los esperara, e sabía que estaban en Calatayud, basteçiéndose de cada día, que non conbenía más esperarlos»: Crónica de Alvaro de Luna, cit., cap. 24, p. 93. 
civil mucho más desarrollada en cuanto a sus técnicas e instituciones que las usuales en la práctica habitual del Estado ${ }^{34}$, en la producción de armas, municiones y otros pertrechos de guerra fue la mediación de los organismos estatales sobre el tejido social lo que provocó resultados sorprendentes, alcanzando niveles de productividad y eficiencia mucho más avanzados que los propios de la empresa civil.

La intervención del Estado en la esfera de la producción no fue ni gratuita ni obedeció a ninguna planificación maquiavélica tendente a aumentar su poder sobre la sociedad. Simplemente se trataba de la puesta en práctica de soluciones de emergencia motivadas por la amenaza de la guerra, soluciones arbitradas ante la peculiar configuración del mercado de armamentos. El mercado de las armas se caracterizaba por una acusada inelasticidad de la oferta respecto de la demanda, una profunda falta de capacidad de reacción a corto plazo por parte de productores y comerciantes ante las súbitas pulsiones al alza de la demanda de armamentos motivada por el estallido de la guerra.

La inelasticidad, la incapacidad de responder al alza brusca de la demanda mediante un incremento proporcional de la oferta venía motivada, desde la esfera de la producción, por la estructura típicamente artesanal de la industria del armamento en el territorio de la Corona de Aragón. Unidades productivas de pequeña escala y escasamente capitalizadas tanto desde la óptica del equipamiento como del capital circulante, fuertemente dependientes del "factor humano", de la habilidad del maestro armero, de la experiencia y destreza del artesano ${ }^{40}$. Se trata de la consecuencia lógica de un mercado sometido a la tiranía de una demanda inestable e imprevisible. El comportamiento aleatorio de la demanda contribuía a desincentivar la introducción de innovaciones instrumentales u organizativas: la inversión de capital podía volverse ruinosa para el productor-empresario ante un período prolongado de inactividad bélica. Sólo en muy determinados centros de la economía-mundo europea como Milán, Nuremberg o Lieja, la concentración de un flujo constante de demanda a escala continental podía dar lugar

39) Me refiero a la muy desarrollada infraestructura bancaria catalana (singularmente la Taula de Canvi de Barcelona que, como hemos visto, posibilitó la fulminante reacción militar aragonesa de agosto-septiembre), y a los instrumentos habitualmente empleados por los círculos mercantiles y empresariales: letras de cambio, etc. Cfr. supra nota 18.

${ }^{40}$ Esta era la situación de la metalurgia, industria madre de la producción de armamentos, incluso en el centro económico de la Corona, la ciudad de Barcelona, donde según Antoni Riera y Gaspar Feliu «el treball del ferro i dels altres metalls va donar lloc a un gran nombre d'oficis diferents, però gairebé tots ells limitats a la producció pel consum local. [...] Sembla $[\ldots]$ que es tractava de menestrals modestos, que no mostren casos d'enriquiment com els que es poden veure en altres gremis»: Jaume SOBREQUÉs (dir.), Història de Barcelona. III. La ciutat consolidada, Barcelona, 1993, p. 175. 
a una transformación autónoma del tejido productivo que, mediante el incremento de la escala de las empresas, su capitalización y la introducción de nuevas tecnologías y mejoras organizativas, incrementase ostensiblemente la productividad y el output total de la industria de armamentos ${ }^{41}$.

Disponemos de algunos indicadores fiables para medir la baja productividad per capita del artesanado del armamento. Así, $v$. gr., el consell de la ciudad de Valencia acordaba en sesión plenaria el 25 de octubre de 1429 que se fabricasen mil hierros de lanzas del tipo conocido como "lunes o esgarradores» ${ }^{42}$ («miges lunes» según otras fuentes). Se contrató para ello el 4 de enero de 1430 a un experto artesano mudéjar, Hamet, "ferrer, moro de Toga, de la baronia d'Arenós " "' que llevaba un año trabajando en Valencia para el baile general, Joan Mercader, y su lugarteniente Francesc Torres ${ }^{44}$. Consciente de sus limitaciones, Hamet sólo se comprometió a fabricar doscientas unidadees, es decir, un quinto sobre las previsiones de consell. Cuando el día 17 de agosto de 1430 se procedió a cancelar todos los contratos de producción de armamento en curso dado el final de las hostilidades, se encontró que Hamet de Toga había fabricado un total de 207 hierros, que entregó a Francesc de Rojals, síndico de la ciudad. La productividad de Hamet de Toga puede cifrarse, pues, entre 0'9 y una media luna al día, según respetase o no la jornada de descanso coránico ${ }^{45}$. Por su parte, en los

${ }^{41}$ Existen muy pocas monografías sobre el tema. La mayoría de las publicaciones son antiguas y dispersas. Destacar el artículo de Philippe CONTAMine Les industries de la guerre dans la France de la Renaissance; l'exemple de l'artillerie, "Revue Historique», 550 (1984), pp. 249-280, y el más completo libro de Claude GaIER L'industrie et le commerce des armes dans les annciennes principautés belgues $d u$ XIIle à la fin $d u$ XVe siècle, París, 1973. Para la armería lom-

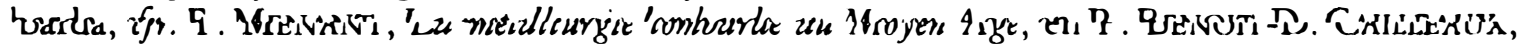
Hommes et traviail du métal dans les villes médiévales, Paris, 1988, pp. 127-161.

42 AMV, Manuals de Consells, A-29, f. 156 r. El 14 de noviembre, el consell reiteraba que "de fet [se] façen fer tantes esgarradores com fer se pusquen" (ibid., f. 159 v.). El 25 de enero, tras la firma del contrato por Hamet de Toga, el consell volvía a insistir en la necesidad de obtener mil lanzas desgarradoras (id., f. 186 r.).

43 AMV, Claveria Comuna, O-12, ff. 185 v. -186 r.

44 El 21 de enero de 1429 cobraba 2.000 ss. de F. Torres por doscientas medias lunas (ARV, Bailia, libro 44, f. 694 r.); el 29 de diciembre de 1429, 540 ss. de J. Mercader por cincuenta y cuatro medias lunas (ARV, Mestre Racional, 47, f. 336 r.).

${ }^{45}$ Según respetase o no, porque los contratos de fabricación de suministros militares en época de guerra no solían respetar los usos consuetudinarios. El 24 de marzo de 1429, en plenos preparativos de la primera entrada en Castilla, Alfonso $\mathrm{V}$ ordenaba desde Lérida a Joan Mercader, baile general del reino de Valencia, que «vista la present, façats fer cinquanta cobreadzembles [...] havent per obrar e fer aquelles tots quants menestrals trobarets en aquexa ciutat qui sien àbils e experts per a la dita obra, los quals, lexades totes qualsevol altres obres, entenguen contínuament, no cessant dia ne nit, en obrar aquelles, a fi que sien acabades lo pus promptament que fer se puxa»: ARV, Real Cancillería, 233, f. 22 v. (el subrayado es mío). La coerción y la alteración de los ritmos habituales de trabajo del artesanado que implicaba este mandato no requieren mayor explicación. 
contratos de fabricación de armaduras, los artesanos establecían un plazo de unos veinte días para librar al cliente una armadura completa ${ }^{\text {th }}$. En definitiva, para obtener las mil medias lunas que inicialmente requirieron, los consellers de Valencia hubieran tenido que esperar, dado el ritmo de trabajo artesanal, casi tres años; y si hubiesen sido mil armaduras, algo más de cincuenta y cuatro.

La irregularidad de la demanda también daba lugar a una típica situación de promiscuidad laboral por parte de los artesanos involucrados en la producción de armamentos. Como raras veces tenían que hacer frente a una demanda sostenida de su especialidad productiva, en tiempos de paz debían dedicarse a menesteres afines no directamente relacionados con la industria de las armas. Así, todo un maestre de fer bombardes de Valencia, Antoni Toldrà, que suministró a la bailía general del reino trenta y tres piezas en la guerra de 1429-30, no tenía ningún inconveniente en forjar y vender las menos heroicas y más humildes azadas y hoces ${ }^{-17}$. Igualmente típico es el caso del artesano que, desde la esfera de la producción de bienes de consumo "civiles", penetra en la producción de armamento ante coyunturas alcistas de su demanda. Es un comportamiento típico de oficios como el de manyà, experto en cerrajería y metalurgia "de precisión», que se hace cargo de la fabricación de armamento técnicamente complejo, como son los martinets de cargar ballestas, artefactos compuestos de múltiples piezas (manivelas, poleas, cuerdas, etc.) que requerían manos hábiles para una correcta fabricación, ensamblaje y puesta a punto ${ }^{48}$.

Tampoco se podía confiar en el comercio de importación para cubrir la demanda insatisfecha. El comercio también se veía perturbado por las bruscas oscilaciones de la demanda y, además, dada la lentitud de los transportes de la época, podía mediar un lapso de tiempo excesivamente largo entre la firma del pedido y la entrega del material como para resultar adecuado a

*6 Joan Villalba, "armer" de Valencia se comprometió ante notario el 6 de abril de 1430 en fabricar una armadura completa para "mossén Johan Riço, cavaller del realme de Cicília». Entre las cláusulas podemos leer: "lo qual arnés le promet donar acabat d’ací a vint jorns, sots pena de deu florins»: ARV, Protocolos, 11.243, s.f.

47 El 22 de mayo de 1430 vende al baile general del reino de València "dues axades $e$ dos legons nous" por 36 ss.: ARV, Mestre Racional, 49, f. 318 r.

48 Eloi Pont, "manyà de la ciutat de València" entrega el 11 de mayo de 1430 "sis martinets de ferre ab sos mascles e arreus" al baile general del reino de Valencia por 264 ss.: ARV, Mestre Racional, 49, f. 316 r. Algunos investigadores tratan de hacer de esta promiscuidad laboral el hilo conductor de sus trabajos, y defienden la necesidad de construir detalladas prosopografías que ayuden a clarificar el iter profesional de los artesanos de la industria militar. Cfr. Alain GIRARDOT, Foundeurs d'artillerie et siderurgistes, une direction de recherche?, en Mines, carrières et métallurgie dans la France médiévale. Actes du colloque de Paris 19, 20, 21 juin 1980, París, 1983, pp. 67-76. 


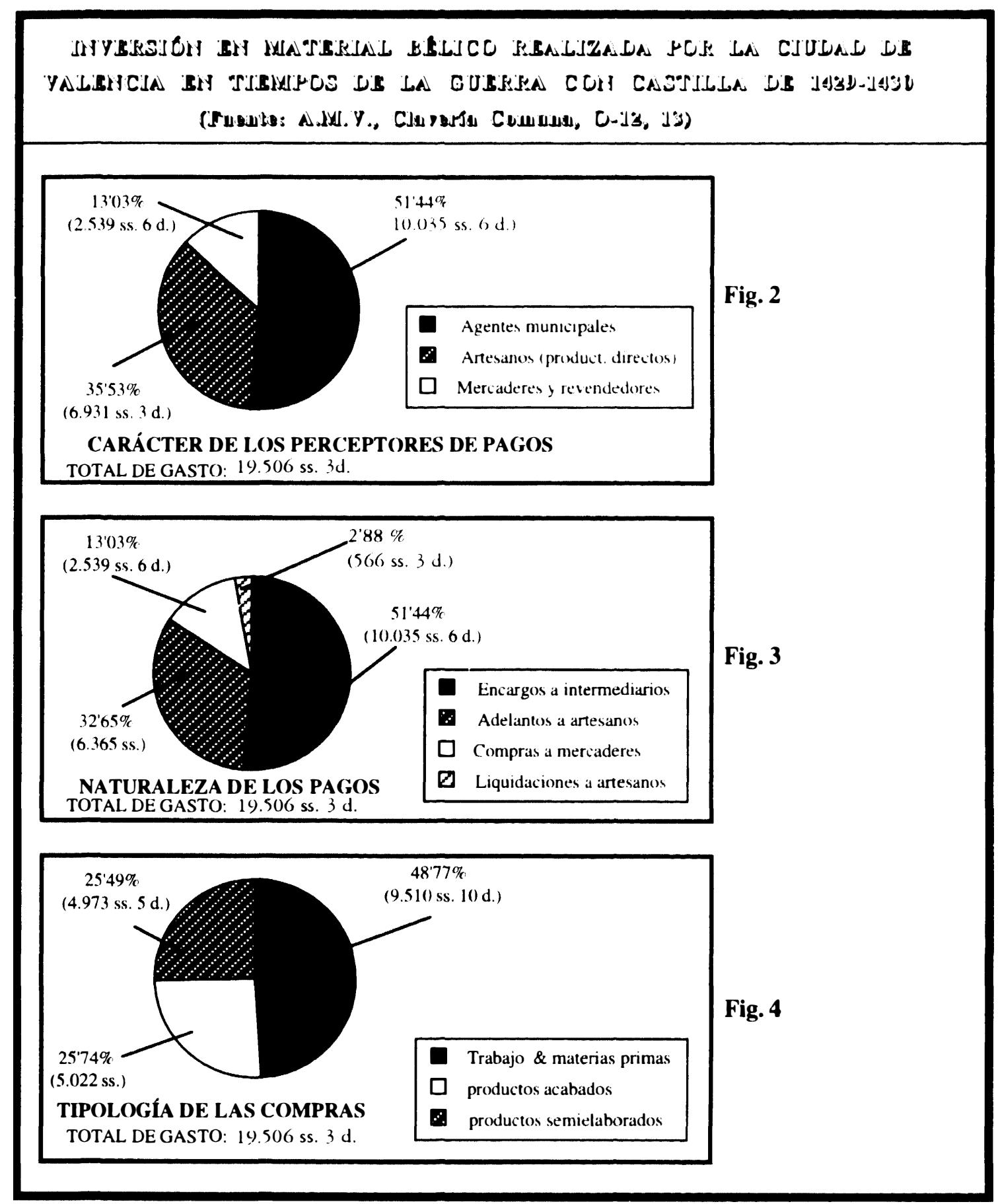

los requerimientos políticos. Por otra parte, el lógico afán de lucro de mercaderes y comerciantes podía motivar en contextos alcistas de la demanda una retirada de bienes de la circulación con ánimo especulativo. Con tal motivo el 29 de julio de 1429 Pere Bou, lloctinent de governador general del reino de Valencia, dictó una provisión en virtud de la cual todas las personas involucradas en el negocio de las armas, productores, mercaderes y ten- 
deros, estaban obligados a hacer públicos los productos en su poder, para evitar que, mediante la ocultación, pudieran "demanar for no degut" por ellos ${ }^{41}$. Se trata de un intento de mantener precios políticos ante una coyuntura fuertemente alcista de la demanda. Y ese mismo afán de lucro, unido a posibles o evidentes filiaciones políticas con potencias rivales, hacía de los comerciantes extranjeros el blanco de todas las sospechas. En noviembre de 1429 se detenía en Alpuente a un tal Ferrán Sánchez, "castellà», y se le apresaban doce armaduras que "passava amagadament» a Castilla. En enero de 1430) se registraba una nave genovesa varada en el Grau de la Mar de Valencia, «en la qual se dehia que havia arneses de mercaders lombarts, e senyaladament de Jordi d'Alza, los quals trametien en Castella als enemichs del senyor rey». Poco después, tras un registro de su casa, se confiscaba al mismo Giorgio d'Alzate (por lo demás un habitual proveedor de la bailía general del reino, avecindado en Valencia desde $1427^{50}$ ) un número indeterminado de armaduras ${ }^{51}$. La dependencia respecto de mercaderes extranjeros resultaba políticamente inaceptable.

Uno de los elementos que de forma más clara pone de manifiesto la insuficiencia de la oferta de armamento a través del mercado viene dado por el hecho de que el suministro de producto acabado (armas y municiones) derivase en buena medida de la movilización del contenido de los arsenales de la corona y de otras entidades armadas de sus reinos ${ }^{52}$. Una oferta dra-

49 "Ara hojats què us fan a saber lo honorable en Pere Bou, lochtinent general de regne de València a tots mercaders, cuyracés, ballestés [e] revenedors qui tinguen armes a vendre: que aquelles tinguen de manifest, mostrant aquelles a aquells qui comprar-les voldran, certificant-vos que si de les armes demanaran for no degut, qui lo dit honorable lochtinent ab lo honorable en Manuel de Palomar, taxaran les dites armes, e segons la dita tatxa faran vendre aquelles, e sots pena a cascú de perdre les armes. E guart-si qui guardar si ha»: ARV, Governació, 4.255 , f. 68 r.

${ }^{50}$ Leopoldo PILES ROS, La población valenciana a través de los «Llibres de avehinament", 1400-1449, Valencia, 1978, p. 861. La familia d'Alzate constituía una sociedad mercantil milanesa cuyas actividades son rastreables desde mediados del XIV, y que en esta época contaban con sucursales establecidas en Milán, Génova, Valencia y Brujas. Giorgio d'Alzate actuaba como representante de la familia en Valencia al menos desde 1418; los acontecimientos de 1430 debieron afectar seriamente a su carrera, ya que la familia le sustituye ese mismo año por su pariente Pietro d'Alzate. Cfr. Patrizia MAINONI, Els meriaders llombards en el regne de València (1390-1460), en Antoni FURIÓ (ed.),València, un mercat medieval, Valencia, 1985, pp. 114-116.

s1 ARV Mestre Racional, 47, ff. 381 v.- 382 v.

$\$ 2$ Alfonso $\mathrm{V}$ movilizó singularmente el contenido de los depósitos militares de les parts marítimes hacia el frente de Aragón. Destaca el transporte de doce bombardas del castillo de Peñíscola a Calatayud, nueve en julio de 1429 (ARV, Mestre Racional, 8.777, f. 58 r.) y otras tres en agosto, junto con 103 "pedres per ops de les dites bombardes" (ARV, Mestre Racional, 9.384 , f. 52 r.-v.; 8.777 , f. 74 v.), que fueron empleadas en la campaña relámpago de agosto-septiembre; el envío (agosto de 1429) a Calatayud por el baile general del reino de 
máticamente insuficiente ante el estallido de cualquier conflicto. Para paliar el déficit de abastecimiento, el Estado se veía obligado a tomar cartas en el asunto.

Las cifras confirman estas aseveraciones. El examen de las distintas contabilidades de las instituciones involucradas en la adquisición de material bélico revela un patrón común de comportamiento, caracterizado por un fuerte intervencionismo político en la producción de armamento como respuesta ante un mismo contexto de oferta inelástica e insatisfactoria. Una comparación entre el gasto armamentístico realizado por el consell de la ciudad de Valencia y la tesorería general de la Corona en tiempos de la guerra que nos ocupa demuestra que se trataba de una estrategia puesta en práctica por todos los poderes públicos para paliar la insuficiencia de la oferta suministrada a través de los mecanismos de mercado. Podemos observar (fig. 2) cómo los mercaderes y otros particulares vinculados a la esfera de la circulación de bienes (botiguers, etc.) aparecen cobrando cantidades de la ciudad en un porcentaje muy bajo, del $13^{\prime} 03 \%$ sobre el valor del total gastado. Mercaderes que en todos los casos pertenecen al ámbito local o esta$\mathrm{tal}^{53}$, lo que demuestra la incapacidad (y la desconfianza) del comercio de importación para resolver a corto plazo los problemas de abastecimiento. Los artesanos casi triplican esta cifra, elevando su participación a un respetable $35.53 \%$ sobre el valor total. El resto, más de la mitad del gasto, es gestionado a través de agentes municipales que aparecen recibiendo pagos en virtud de comisiones o sindicaturas para encargarse de la compra de material o de la supervisión de procesos productivos; por ello su porcentaje

Valencia de cien celadas custodiadas en el palacio real de dicha ciudad (BCCV, Fondo Mayans, 677, f. 204 v.); 104 "caxons d'estralles", conteniendo 50.930 proyectiles de ballesta de este tipo remitidas por "los visreys de Sicília», que llegaron a Zaragoza el 25 de febrero de 1430 de la mano de "certs moros de València en XXI adzembles" (ARV, Mestre Racional, 49, ff. 343 v. -344 r.). El rey había ordenado desde Calatayud a los virreyes el 3 de agosto de 1429 que le enviasen "totes les estralles que aquí sien nostres en la pus presta e sugura [sic] via que sia possible" (ACA, Cancilleria Real, 2.713, f. 20 r.); tardaron, pues, casi siete meses en llegar. La Diputaició del General del principado de Cataluña jugó un papel fundamental en la citada contraofensiva, al prestar al rey entre julio y agosto de 1429 «bombardes, bussons e rotlons de matall, e les pedres de les dites bombardes" (ARV, Mestre Racional, $8.777,78$ v. -79 r.), "rodes de carreta, fusells [de carros] e talles" (ARV, Mestre Racional, 8.778 , f. 92 v.) por un valor de 2.489 ss. 6 d. de Barcelona. Posteriormente prestaría también "la bombarda grossa appellada Sent Jordi, de pes de C quintars" (A.R.V., Mestre Racional, 8.777, f. 130 r.), evaluada en unos 30.000 ss. de Barcelona, junto con 524 libras de pólvora de bombarda (ARV, Mestre Racional, 8.778, ff. 95 v.-96 r.).

${ }_{33}$ En total, son cinco individuos, cuatro ciudadanos de Valencia (Salvador Xulbe, «specier», Arnau Pahoner, «botiguer», Francesc de Muntpahó, «mercader» y Tristany Joan) y un ciudadano de Barcelona (Francesc Vila, "mercader»): AMV, Claveria Comuna, O-12, ff. 182 r., 185 r.-v., 188 r., 196 r. 
se identifica con el $51^{\prime} 4$ \% correspondiente a los encargos a intermediarios presente en la fig. 3. Se trata de intermediarios institucionales: la administración pública adquiría la fisonomía de una empresa comercial, destacando factores para la captación de recursos y/o la producción de bienes. Tal vez el dato más relevante venga dado, sin embargo, por los porcentajes de la fig. 4. Podemos apreciar que sólo la cuarta parte del gasto se corresponde con la compra de producto acabado (especialidad de mercaderes y tenderos), mientras que la compra de productos semielaborados, unida a los pagos en concepto de trabajo y materias primas, supone las otras tres cuartas partes. Esto equivale a reconocer prácticamente un $75 \%$ de intervención municipal en la producción de armamentos, porque lo que la ciudad está comprando o pagando son factores de producción por separado, que exigen tareas de coordinación y dirección de empresa para la obtención del producto acabado, tareas que asumirá el municipio a través de sus agentes.
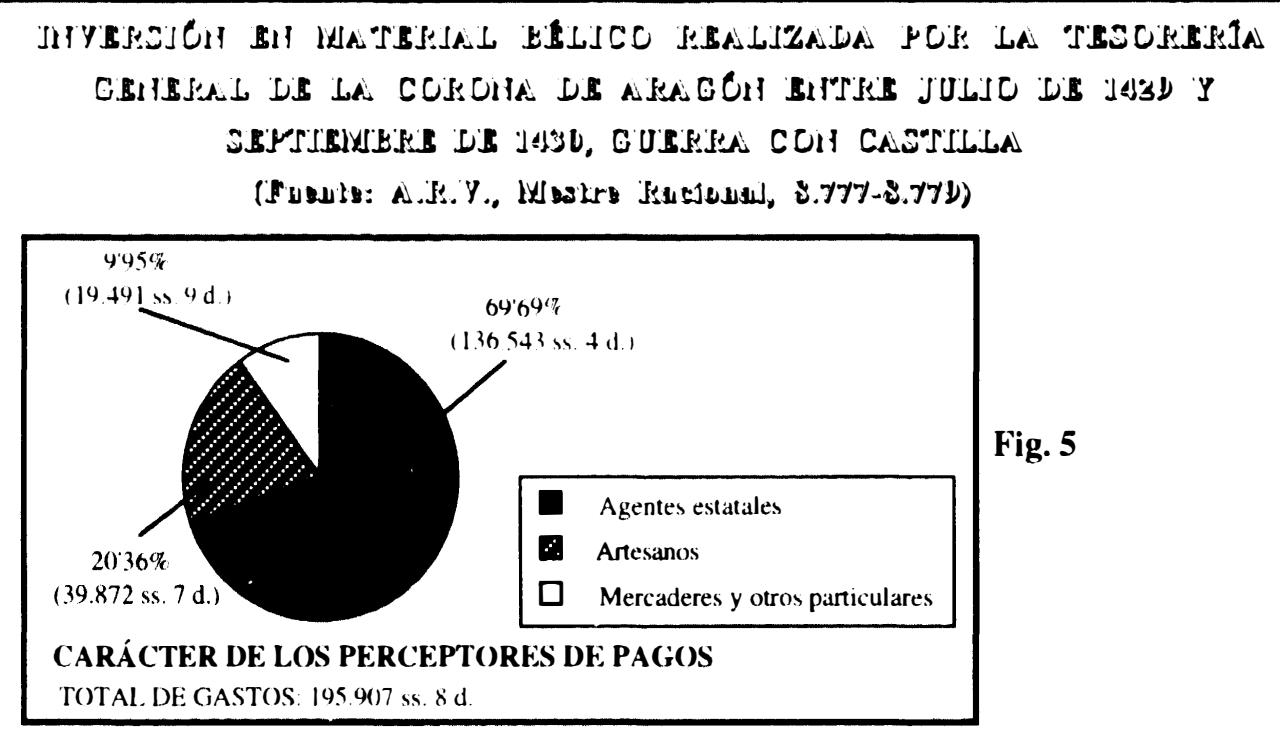

Si analizamos ahora la contabilidad de la tesoreria general (fig. 5), podemos ver que no sólo se repiten las pautas observadas en la contabilidad del consell valenciano, sino que estas aparecen más acentuadas. Dejando a parte el hecho de que la tesorería gasta en la adquisición de material bélico casi once veces más que la ciudad de Valencia, podemos comprobar que la cuota de participación de los comerciantes en el suministro se ve reducida a un exíguo 9'95\%, frente al 13'03\% que suponía su participación en el gasto realizado por el consell. Los pagos directos a artesanos siguen siendo más importantes que las compras a mercaderes, duplicándolas en cuantía, pero lo más relevante es el crecimiento de la cuota gestionada por los agentes institucionales, en este caso oficiales de la tesorería, que crece de un 
$51^{\prime 4} 4 \%$ al 69$)^{\prime} 69 \%$ del total invertido, lo cual quiere decir que la administración central está tratando de obtener un control más estrecho del abastecimiento y de los procesos productivos. El Estado, a todos sus niveles, no se arriesga a ceder estas parcelas a la iniciativa privada, ya sea artesanal o mercantil. La tesorería general tenía la responsabilidad directa del sostenimiento del teatro principal de operaciones, lo que dará lugar a las formas más intensivas de gestión de la producción e intervencionismo estatal. Y los acontecimientos, como relatábamos anteriormente, demuestran que el rey Alfonso $\mathrm{V}$ hizo un uso inteligente y exhaustivo de los recursos de la Corona. Resta por analizar cuáles fueron los productos de dicha intervención.

\section{INTERVENCIÓN ESTATAL EN LA PRODUCCIÓN DE ARMAMENTO; GUERRA DE 1429-1430.}

Si prestamos atención a los porcentajes de la fig. 3, podemos apreciar que una de las medidas prioritariamente puesta en práctica por las instituciones para incrementar el output de los talleres artesanos consistió en la inyeciión de capitales en los mismos, bajo la forma de anticipos en metálico sobre el coste previsto de la producción concertada: prácticamente un tercio del presupuesto del municipio de Valencia destinado a la adquisición de pertrechos bélicos. La capitalización de los talleres artesanales permitía a estos obtener la materia prima extra implícita en los grandes pedidos institucionales, y/o la contratación de personal eventual, cualificado o sin cualificar, que permitiese satisfacer el encargo en el menor tiempo posible. Esta medida, unida al incremento de la división del trabajo entre los talleres artesanales mediante la planificación de la producción y la asignación de tareas complementarias a colectivos artesanales distintos ${ }^{54}$, fue la medida

5.t Fórmula especialmente adecuada en los procesos de fabricación de piezas susceptibles de estandarización y producción en serie, como proyectiles de ballesta o lanzas. De esta forma, el baile general del reino de Valencia encargó a Abrafim Gua, "moro e ferrer de la moreria de València», la fabricación de "çinquanta ferres de lances o glavis [...] a ops de cinquanta lances largues per als castells reyals de aquest regne, e a ops de mon officin (ARV, Mestre Racional, 47, f. 328 r.), mientras que Joan Vicent, "lancer de la ciutat de València» le suministraba «cinquanta astes de lances largues obrades per enastar en aquelles los L ferres que foren per mi comprats de Abrafim Gua, moro ferrer de la moreria de València» (ibid., $\mathrm{f}$. 328 v.); Joan Vicent también cobró 216 ss. por « LIIII astes de freix que de aquell he comprades, a for de IIII sous per cascuna asta, e enastar aquelles en aquells LIIII ferros de esgarradores o lunes que yo he fetes fer a ops e forniment dels castells reyals de aquest regne" (ARV, Mestre Racional, 49, f. 331 v.), es decir, los 54 "ferres de miga luna acerats" que encargó fabricar a Hamet de Toga (ibid., f. 336 r.). Igualmente obtuvo 1.000 proyectiles de 
más aplicada en las zonas ubicadas «a retaguardia» del conflicto o en lugares que, como Valencia, pese a su carácter de área limítrofe con el enemigo, no constituían el teatro principal de operaciones. Se trata de técnicas homólogas a las practicadas por los mercaderes-empresarios, los verleger protagonistas del proceso de protoindustrialización ${ }^{\text {ss }}$, que lograban incrementos del producto global sin alterar la base artesanal de la producción. La coordinación de las labores de multitud de talleres artesanos, unida a su capitalización mediante anticipos en moneda o materia prima podía producir excelentes resultados al operar economías de escala, aumentando simultáneamente el volumen de la producción y disminuyendo los costos por unidad de producto. Este procedimiento contaba, sin embargo, con dos inconvenientes: a) la imposibilidad de una supervisión directa de todos los procesos por parte de las autoridades contratantes al operar sobre una red artesanal descentralizada; b) la iniciativa en cuanto a la gestión de los inputs de capital quedaba en manos de los maestros artesanos, a nivel de sus respectivos talleres. La incapacidad de una supervisión completa de los procesos de producción podía derivar en una disfunción general del sistema si las partes implicadas trabajaban a diferente ritmo. Y estrechamente relacionado con esto, el hecho de que el artesano fuese responsable de la gestión del capital estaría en la base de los propios ritmos diferenciales dado que, si bien un maestro podía emplearlo adecuadamente, contratando personal eventual o constituyendo sociedades con otros maestros del ramo, aquellos que se limitaban a la ineludible compra de materia prima extra no incrementaban para nada la productividad de su taller.

Ambos riesgos resultaban intolerables en las inmediaciones del teatro principal de operaciones. Por ello, allí encontraremos las formas más innovadoras de gestión de la producción, bajo supervisión directa del rey y de los miembros de sus oficios. Aquí se trataba, sobre todo, de ahorrar tiempo, factor inapreciable en coyuntura bélica cuyo ahorro no quedaba garantizado

\footnotetext{
ballesta mediante coordinación de tareas complementarias asignadas a diferentes artesanos: Joan Torres, "ferrer", fabricó "mil ferros de viratons", mientras que Fortuny Pérez, "torner" se encargaba de ultimar «mil astes de faig noves, obrades, empenades e enastades en los dits ferres» (ARV, Mestre Racional, 49, f. 318 v.).

"Teniendo muy en cuenta que esta "penetración del capital en la esfera de la producción» la estamos constatando en espacio urbano, no en el ámbito rural que monopoliza los trabajos de los principales teóricos de la protoindustrialización. $C f r$. Peter KRIEDTE-Hans Medick-Jürgen SCHLumbohm, Industrialización antes de la industrialización, Barcelona, 1986; Peter KRIEDTE, Feudalismo tardío y capital mercantil, Barcelona, 1986. Para las críticas a la dimensión agrarista de la protoindustria, cfr. los trabajos Protoindustrialización. Un concepto abusivo de de D. C. Coleman y Ciudades e industria rural de M. BerG, P. Hudson y M. SONENSCHER, publicados en el dossier dedicado al tema por la revista "Debats", 12 (1985), pp. $47-56$ y $60-61$.
} 
por el sistema de trabajo por encargo. Los elevados requerimientos de productividad determinaron una profunda alteración de la estructura artesanal de la producción. El Estado logró, mediante la transferencia de su propia tecnología organizativa, crear manufacturas fabriles de elevado rendimiento y output de producción. Grandes unidades altamente capitalizadas de estructura piramidal, donde las distintas labores se ecuentran espacialmente concentradas y fuertemente integradas dentro de una neta división del trabajo. De una estructura horizontal y descentralizada de la producción, extensiva, se pasa a otra vertical e intensiva.

El tiempo apremiaba. Para responder con contundencia a la agresión castellana de julio de 1429 había que poner manos a la obra. Alfonso V ordenó una movilizacion selectiva de hombres (artesanos cualificados) y materiales (materias primas y productos semielaborados) hacia Zaragoza y Calatayud, para suplir in situ, en el propio teatro de operaciones, las deficiencias del abastecimiento a través del mercado. El 14 de julio de 1429 ordenaba desde Calatayud al tesorero Francesc Sarçola, a la sazón en Barcelona, que «vista la present, nos trametats cuytadament a la ciutat de Çeragoça un o dos mestres de lances ab tres o quatre mília lances d'armes, car nós provehirem que de Çeragoça vinguen açí com pus prest sia possible [...] com lo cas requira més acceleració que tardança" " ${ }^{56}$. Las deficiencias del mercado fundamentaban la orden: el secretario Francisco d'Arinyo sólo había podido adquirir en Valencia 500 lanzas largas sobre las 5.000 que el rey le había encargado comprar ${ }^{57}$. Por ello el monarca reiteraba el día 26 de

56 El tesorero se hallaba gestionando la obtención de créditos y la contratación de ballesteros y gente de armas (estudiado por Jorge SÁIZ SERRANO, Estado y poder militar...cit.). En la misma carta, el rey impetraba al tesorero que «no perdats punt ne hora, ans dia e nit treballets en los affers per quan sou stat tremés, car segons que per altres vos havem scrit, lo rey de Castella és ja prop la frontera, e cuyta per entrar en nostre regne, e cové que al pus prest que sia possible nos tremetats la gent que aquí haver se puschan: ACA, Cancillería Real, 2.713 , f. 2 r. Hay que tener presente el uso que se hace de los adverbios aquí y ací se emplea la forma ací para indicar el lugar desde el cual se está escribiendo, mientras que aquí indica el lugar donde radica el destinatario.

"7 En carta fechada el 26 de julio en Calatayud, el rey comunicaba a su secretario, aún en Valencia, que «havem plaer de les çinch-centes lançes que.ns trametets»: BCCV, Fondo Mayans, 677, f. 204 r. Valencia falló por completo en el suministro de armamento. Barcelona se perfilaba como el único centro capaz de dar la talla ante los requerimientos del rey, que así se lo transmitía a F. d'Arinyo en la misma carta ( "secretari: vostres letres havem reebudes de XXII e XXIII de juliol, e quant a les coses que aquí no haviets pogut haver, ço és, bombardes, pólvora, lançes, compliment de viratam e algunes ballestes de leva e martinets, nós hi provehim per via de Barcelona»-ibid., f. 203 v.-). Hay que tener muy en cuenta para evitar distorsiones que Valencia ya tenía bastante con ocuparse de sus propios problemas al encontrarse en primera línea de combate y tener la responsabilidad directa de abastecer un elevado número de castillos a lo largo de centenares de kilómetros de frontera. Barcelona, a retaguardia del conflicto, quedaba libre para poder taponar brechas allí donde fuera requerida. 
julio al tesorero que le enviase "spatxadament les coses de que us havem

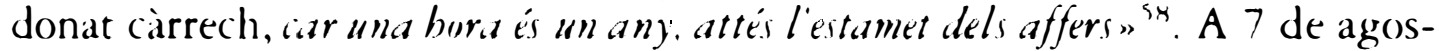
to notificaba a Pere Ferrer, agente de la tesorería radicado en Zaragoza, que le enviaba a "en Pere Font [maestre de fer bombardes de Barcelona] per fer dues bombardes grosses", y que había avisado "al lochtinent de batle general de València e al batle general de Tortosa que trametan aquí [a Zaragoza] al merino lo coure del qual se deuen fer les dites bombardes" ". La disponibilidad de stocks estratégicos de material, acumulados en años anteriores durante los preparativos de la abortada expedición a Italia, resultó clave en la rapidez de respuesta aragonesa: Francesc Torres, el llowtinent de batlle general de Valencia, había comprado a tal efecto entre el 10 de enero y el 26 de abril de 1429) unas 12.056 libras de cobre "de Romania" "(1) que fueron de inmediato remitidas a Zaragoza para la fabricación de las bombardas.

Los agentes de la tesorería comenzaron a realizar grandes compras de materias primas y productos semielaborados. Joan Çafont, factor radicado en Barcelona, compró entre julio y diciembre de 1429) "lances longues, ferres per aquelles, tatxes, pales, talloles, martinets, fils de ferre e de lautó, salmitre, çoffre, carbó de salze, coure, stany, astes de passadors, talles e altres averies per a les dites coses necessàries" por valor de 63.263 ss. $4 \mathrm{~d}$. barceloneses ${ }^{(1)}$. En el mismo período Jaume Amigó, "comprador de casa del senyor rey", gastaba entre 4.748 ss. $8 \mathrm{~d}$. de Jaca "per rahó de les messions de compres de fusta, clavo e altres coses, e jornals de mestres d'axa e picapedrés que ha fetes e pagades de manament del dit senyor per ops de les artillaries que ha manada fer en la ciutat de Calataiú, e altres obres en los lochs de frontera" ${ }^{(2)}$, y 10.952 ss. 8 d. "per rahó de diverses lances largues, obrades e per obrar, bombardes, pedres per aquelles, ballestes, passadors e moltes altres armes e artelleries qui són estades aportades de les ciutats de Çaragoça, de València e castell de Peníscola a la dita ciutat de Calataiú " ${ }^{63}$. Francesc de Canals, de Vic, y Bertomeu Arguimbau, mercader de Barcelona, proporcionaban al tesorero $36 .(0)()$ astas de proyectil de ballesta, que fueron enviadas para su acabado al baile general del reino de Valencia ${ }^{64}$,

is ACA, Cancilleria Real, 2.713, f. 10 r. (el subrayado es mío).

5) lbid, , f. 27 r.

6) ARV, Bailia, libro 44, ff. 692 r., 689 r. y 689 r.-v.

(1) ARV, Mestre Racional, 8.777 ,ff. 78 v. -79 r., 106 r., 133 r.

62 El documento especifica que las artillerías se fabricaron "per rahó de la entrada que.l dit senyor rey ha feta derrerament en lo regne de Castella, acompanyat de molts barons, nobles, cavallers, gentilshòmens e altra gent, a cavall e a peu ": ARV, Mestre Racional, 8.777, f. $114 \mathrm{r}$.

6i ARV, Mestre Racional, 8.777, f. 113 v.

${ }^{64}$ Ibid., f. 79r. Al mismo tiempo, el rey escribía al lloctinent Francesc Torres comunicándole que "nós havem scrit a.n Johan Çafont, de nostra thesoreria, lo qual és de present en 
quien disponía de al menos 15.185 punt as de proyectiles almacenadas"s.

Los resultados no se hicieron esperar. El 19) de julio, sólo cinco días después de haber sido cursada la orden del rey, ya se encont raban en Calatayud al menos dos lancers de Barcelona, Berenguer Arnau y Miquel Cors, y en 57 días (hasta el 14 de octubre, "comprés lo retorn tro a sa casa a Barcelona»), trabajando junto a otro especialista barcelonés del ramo, Martí de Verga (que trabajó 49 días), aprestaban no menos de 3.()()() lanzas largas" de caballería para el ejército.

Zaragoza fue, sin embargo, el mayor centro de actividad durante los primeros meses de la guerra. Alli se ubicaron tanto los grandes depósitos militares que abastecían el frente como la industria pesada, centrada en la producción y el acabado de armas de fuego. Ambas actividades, almacenaje y producción, se beneficiaron enormemente de la intervención monárquica en los bienes y rentas del arzobispado, secuestrados tras la detención de su titular a principios de año ${ }^{67}$. El rey empleó a fondo las instalaciones de la Iglesia para fines muy poco espirituales. El decapitado clero de la capital aragonesa asistía atónito e impotente a un espectáculo demoníaco de colosales magnitudes: ¡el palacio del arzobispo, convertido en arsenal militar ${ }^{68}$ ! ¡El monasterio de los frailes franciscanos, fábrica de bombardas ${ }^{\left.()^{(}\right)}$¡ El fuego

la ciutat de Barcelona, que de continent trameta a vós les astes de viratam que nós en son poder havem lexat partints de Barcelona, per ço que vós, reebudes aquelles, hi féssets metre ferros»: ACA, Cancillería Real, 2.713, f. 18 r. La división del trabajo funcionaba a escala de toda la Corona.

6s Nuevamente los preparativos para la armada y la expedición a Napoles, puestos en marcha desde el regreso de Alfonso $\mathrm{V}$ a la península Ibérica en 142.3, beneficiaron la pronta respuesta aragonesa en la guerra de 1429-30). Entre 1424 y 1429 (sin contar los encargos realizadas ex profeso para la guerra), el baile general del reino de Valencia y su lugarteniente ordenaron la fabricación de al menos 67.899 puntas de proyectiles de ballesta, de las que presumiblemente se enastaron 52.714, además de la adquisición en el mercado de 11.748 proyectiles acabados: ARV, Mestre Racional, 44 (ff. 282 v., 286 v., 290 v., 317 r., 318 r., 321 r., 322 v.), 45 (ff. 292 r., 322 r., 331 r., 347 v.-348 r.), 46 (140 r.); Bailia, libro 44, ff. 641 r., 678 r., 680 v.

st ARV, Mestre Racional, 8.777, f. 113 r., f. 131 r.; 9.384, f. 57 r.

67 Aloso de Argüello, arzobispo de Zaragoza fue detenido el 4 de febrero de 1429 por sus contactos con Álvaro de Luna, siendo presumiblemente asesinado durante su cautiverio. El rey aprovechó maquiavélicamente la circunstancia para secuestrar las rentas y bienes del rico arzobispado. que se convirtieron en firme puntal para el sostenimiento del frente aragonés, asunto que he estudiado en colaboración con Jorge Sáiz Serrano (Actividad militar y crecimiento del Estado, cit.).

68 Antoni Morató, "fuster de la ciutat de Barcelona" fue el encargado de "fer mudar certes càrregues de les artelleríes del dit senyor [rey] de casa d'en [Nicolau de] Casafranqua a les cases de l'arquabise de Saragoça", pagando "en compra de teules [...] e jornals de hòmens que han ajudat a stibar aquelles e altres" 282 ss. 9 d. de Jaca: A.R.V., Mestre Racional, 9.384, ff. 51 v. -52 r.

69 ¿En represalia, quizá, de la conducta del arzobispo, miembro de dicha orden? 
del infierno en el seno de su claustro! El punto culminante del proceso tendría lugar en enero de 1430) cuando, tras dos días de esfuerzo agotador, un equipo de treinta mozos de cuerda dirigidos por Joan Ravaça y Cebrià Rovira, fusters de Barcelona, lograba depositar «en lo Tinell del dit Palau" la gran bombarda "Sent Jordi", de 100) quintales de peso, prestada por la Diputació del General de Catalunya ". Mientras tanto, en el monasterio de franciscanos se fabricaron cuatro grandes bombardas y trescientas piezas portátiles ("quatre grans bombardes e CCC buçons»"), actividad en la que intervinieron cuatro especialistas y un aprendiz ${ }^{2}$ entre agosto de 1.429 y febrero de 1430, mientras que cuatro carpinteros y un herrero ${ }^{72}$ se encargaban de aparejar gruas, afustes y "quatre carros, cascú de quatre rodes ferrades [...] en los quals devien ésser portades les dites quatre bombardes ${ }^{74}$. Pere Font, el maestro fundidor de bombardas, y sus colaboradores realizaron un gasto enorme "en compra de coure, fusta, clavo, ferre e altres coses" necesarias para la fabricación de las 304 bocas de fuego y sus complementos, cifrado en $27.7(06$ ss. 2 d. de Jaca y 1.155 ss. de Barcelona, incluyendo sus salarios `s. Con ellos debió de trabajar, aunque llegó a territorio de la Corona en diciembre de 1429, "Antoni Maroman [Mereman en otros docu-

"ARV, Mestre Racional, 8.777 , f. 130 r. En enero de 1430, Pere Ferrer gastó 256 ss. 2 d. de Jaca "per rahó de les messions e despeses que de manament del dit senyor havia fetes en la ciutat de Saragoça [...] en traure de barqua, metre e muntar en lo Palau de l'Arquabisbe la gran bombarda del General de Catalunya, que.l dit senyor havia manat portar en la dita ciutat, ço és, en salari de XXX // bargants qui per dos díes havien treballat en traure la dita bombarda de barqua e muntar aquella de la hora [sic] del riu al dit Palau, e metre aquella en lo Tinell del dit Palau, e en salari d'en Ravaça e d'en Cebrià Rovira, fusters, los quals havien treballat ensemps ab los dits bargants en lo dit lavor per II díes cascú, e en altres salaris e coses, segons que en lo dit albarà se conté, lo qual restituesch en la present data»: ARV, Mestre Racional, 9.384, ff. 68 v.-69 r.

${ }^{7}$ El bursó (con innumerables variantes ortográficas: buşó, burģó, burgot, bogó, etc.) era indudablemente un arma de fuego portátil, como lo atestigua la documentación coetánea. Así, en 1429 el baile general del reino de Valencia registraba la compra de 269) "pilotes de plom buydades en motles que [...] he comprades $a$ ops de les bombardes petites o burgons qui són en lo dit castell [de Xàtiva]”: ARV, Mestre Racional, 47, f. 325 r.-v. (el subrayado es mío).

72 El ya citado Pere Font, "bombarder de casa del senyor rey", "un moço seu», Vicent Pujol "ajudant de l'offici del dit en Pere Font" y Pere Amat «ajudant del dit offici»: ARV, Mestre Racional, 9.384, f. 48 r.

${ }^{73}$ Los carpinteros son Cebrià Rovira y Bernat de Montpadrós, "fusters de la ciutat de Barcelona" (ARV, Mestre Racional, 8.777, f. 81 r.), Berenguer Montserrat, "fuster de Barcelona” y Joan Ravaça, fuster [...] vengut de la dita ciutat de Barcelona" (ibid., f. 79 r.v.). El herrero es Gabriel Colomer «ferrer de Barcelona» (id., f. 80 v.)

74 ARV, Mestre Racional, 9.384, f. 67 r.

75 Ibid., ff. 48 r., 49 r.-v., 66 v.-67 r.; 8.777 , ff. 79 r.-v., 80 v., 81 r. 
mentos], alamany bombarder" ". Caso singular es el de "mestre Paschal Steva, fuster de casa del senyor rey". Este carpintero había partido de Valencia hacia Calatayud el 27 de mayo de 1429 , habiendo sido requerido "per parar e desparar les tendes del dit senyor" " en el transcurso de la expedición "pacífica» a Castilla del mes de junio. El estallido de la guerra, que le sorprendió en el frente, le obligó a colaborar estrechamente en los preparativos artilleros previos a la segunda incursión. De esta forma le vemos comprando madera "per guarnir VII bombardes de coure" y otros gastos menores por valor de 615 ss. 2 d. de Jaca, labores en las que fue ayudado por otros tres carpinteros valencianos, Vicent Llombart, Martí Penyaflor y Francesc de Montserrat, llegados a Calatayud a mediados de julio $^{78}$.

A finales de 1429, un segundo foco de industria pesada se instaló en Tortosa, donde Pere Torroella, «fuster de Barcelona» fue "ordenat per lo senyor rey a administrar la obra de certs molins de sanch qui.s fan en la dita ciutat per obs e servey del dit senyor". Se trataba de cincuenta molinos de sangre ${ }^{79}$ que el rey pensaba destinar a las guarniciones de los castillos de la frontera de Aragón con Castilla, de cara a la previsible ofensiva castellana de la primavera siguiente. Pere Torroella obtuvo todo un récord de productividad, teniendo en cuenta la complejidad de los artefactos a construir, puesto que fabricó los 50 molinos en unos tres meses. Comenzó a trabajar en diciembre de 1429, y su último envío, que completaba la cifra del encargo, llegó a Zaragoza el 27 de febrero. Para ello trabajó al frente de un extenso equipo de colaboradores, e invirtió 21.853 ss. $11 \mathrm{~d}$. de Barcelona en «compres de diverses sorts de fusta, ferramenta, clavo, loguers de diversos obrers, axí mestres d'axa, fusters, serradors, torners com picapedrers e altres messions necessàries ${ }^{80}$. La rapidez se apoyó, además, en el establecimiento de una neta división del trabajo a escala de la Corona, puesto que $v$ gr. Barcelona suministró un gran número de muelas para los molinos ya acabadas. Además, hubo de

76 Las cuentas de la tesorería registran en diciembre de 1429 el pago de 220 ss. de Barcelona a "Anthoni Maroman, alamany bombarder, los quals lo senyor rey, ab albarà d'escrivà de ració scrit en Tortosa a XXXI dies de deembre de l'any MCCCCXXX li manà donar en esmena de les messions e despeses que ha fetes de manament del dit senyor partint de la sua terra per venir ací a son servey": A.R.V., Mestre Racional, 8.777, f. 126 v. Se trata del 31 de diciembre de 1429, porque el documento está fechado según el año de la natividad.

77 ARV, Mestre Racional, 9.823 (3), f. 25 v.

78 ARV, Mestre Racional, 8.777 , ff. 56 v. y 73 v.

79 Llamados así porque su fuerza motriz venía constituida por el impulso animal o humano, lo que los hacía idóneos para operar en fortificaciones, habitualmente desprovistas de reservas suficientemente adecuadas de agua como para mover ruedas hidráulicas.

${ }^{80}$ ARV, Mestre Racional, 8.777, f. 129 v.; 8.778, ff. 70 r., 79 v. 
establecerse cierto tipo de estandarización del producto, puesto que los molinos eran enviados sin ensamblar a Zaragoza. Era en la capital aragonesa donde se procedía a su montaje, ensayo y puesta a punto antes de ser distribuidos por los castillos de la frontera: las piezas debieron de construirse sobre la base de cierta homologación que permitiera una fácil reposición o intercambio, particularmente por lo que respecta a las muelas ${ }^{81}$. Pere Torroella tuvo tiempo, además, de fabricar en enero de 1430 una grua (cabria) de considerables dimensiones (cuatro postes de 2() palmos de alto, unos 3'9 metros, unidos mediante un travesaño) "per ops de la bombarda grossa appellada 'Sent Jordi' " ${ }^{x 2}$ que, recordemos, pesaba 1()() quintales (cerca de $4{ }^{\prime} 2 \mathrm{tm}$.).

Hubo otros movimientos de artesanos no menos espectaculares pero sí más apegados a la tradición, como fueron los relacionados con la realización de obras de reparación y acondicionamiento de fortalezas. Aquí el papel del artesanado local, predominantemente mudéjar, es más importante. Un total de veintitrés carpinteros, de los cuales diecisiete son mudéjares autóctonos (en su mayoría de Zaragoza), cuatro valencianos y dos barceloneses trabajaron en al menos siete castillos y plazas fuertes, realizando mantellets, verdesques y empalizadas (palenibs) ${ }^{x}$. Este predominio del artesanado local tiene

*i El transporte de los molinos se hizo por secciones. $V$. gr., el 19 de febrero de 1430 se fletaba la gabarra de "Mahomat Almoreso, moro de Miravet, raiz de càrrava" en la cual "ha carragats XIIII cosos de molins de sanch ab forniment de moles e taulam e rodes per forniment d'aquells e altres": ARV, Mestre Racional, 8.778, f. 74 v (el subrayado es mío).

\%? Ibid., f. 79) v.

83 Entre julio y agosto"Azmet Lancero, Asmet Cabanyes e Azmet Cabanyes, menor de díes», "Mahomat Cabanyes, de Saragoça, e [...] Mahomet Lancero, moros mestres de fer artelleríes", al parecer todos emparentados, se dedicaron en Calatayud a tales menesteres; "Jucé Pex, Mahomà Falcó, Mahomà el Bello e [...] Moferrix de la Frarig, moros de la ciutat de Saragoça, fusters" realizaban obras ("verdesques e altres coses») en el Castillo de Cetina, maltrecho tras ser atacado por la cabalgada de Álvaro de Luna; "Alí Cabanyans, Hamet de l'Almunyan, Abrahim de Ramí, Abrahim de Rondí e Mahomat de Galí, moros fusters de la ciutat de Saragoça” invierten 30 días "en fer palenchs, verdesques e altres obres" en la villa de Ateca, clave en el acceso a Calatayud desde la posición del ejército castellano en los mesos de juliol e agost", donde también trabajaron Miquel Arbúcies y Antoni Morató, carpinteros de Barcelona (éste último ayudado por "Jusen, moro»). Miquel Arbúcies con posterioridad permaneció dos meses en el castillo de Ciria «per fer verdesques e mantellets e altres obres al dit castell necessàries». "Jucé Peix" carpintero mudéjar de Zaragoza al que hemos visto trabajando quince días en el castillo de Cetina, estuvo otros treinta junto a "Abrahim de Mediana, moro de Calatayú", también carpintero, "en lo castell de Nuévalos, en fer verdesques e altres coses per lo // dit castell"; "Jucé d'Abrea, moro de la ciutat de Çaragoça» se encaminaba en octubre hacia el conquistado castillo de Borobia, guiado por Federico de Sicilia, capitán del mismo Los cuatro carpinteros valencianos que lideraba Pasqual Esteve, además de fabricar afustes de bombardas, anduvieron 54 días «axí en lo regne de Castella, en la ciutat de Calataiú com en altres lochs». Cfr. ARV. Mestre Racional, 8.777 , ff. 58 v., 90 r., 112 r.; 8.778 , f. 58 r.; 9.384 , ff. 48 r. -49 r. 
fácil explicación, y más si atendemos a las fechas, puesto que casi todos ellos entran en servicio en julio. En estas fechas la prioridad era detener la ofensiva castellana. Es lógico que el artesanado local, el más rápidamente movilizable, cargara con el peso del acondicionamiento de los castillos y la preparación de toda clase de obstáculos y defensas, singularmente en torno a Ateca, clave en la ruta de acceso del ejército castellano a Calatayud. Especial comentario merecería el predominio absoluto de los mudéjares entre el artesanado local reclutado con fines militares, situación paralela a la observada por los investigadores en el vecino reino de Navarra ${ }^{\text {8. }}$.

No obstante, aunque la realización de preparativos defensivos involucrase un mayor número de artesanado que la producción de armamento, no deja de constituir una actividad de tipo tradicional frente a las novedades apreciables en este último sector. En este contexto, entiendo por tradición el recurso al artesanado para la construcción y fortificación de castillos, al igual que su participación en las labores de asedio a ciudades y fortalezas, donde suele enmarcarse la fabricación de armamento pesado en las guerras medievales. Imponderables de tipo físico en el primer caso (el castillo no puede ir al artesano, el artesano debe ir al castillo) y económico en el segundo (dada la penuria de infraestructuras, y el gran tamaño de las máquinas de asedio, resultaba más lógico construirlas a pie de sitio y preferentemente con materiales tomados de los alrededores) explican que encontremos artesanos cualificados trabajando en los escenarios de combate desde las épocas más remotas, como tambiér. los encontramos en la guerra de 1429-1430. Sin embargo, este conflicto se desmarca respecto de la tradición medieval en la meticulosa planificación de la guerra realizada por parte de la monarquía, apreciable en la independencia relativa del lugar de fabricación del armamento pesado (Zaragoza) y equipamiento complementario (Tortosa) respecto de su lugar de uso (frontera castellana), utilizando el eje fluvial del Ebro. La mejor imagen para captar la modernidad de los métodos y de la estrategia militar de Alfonso $\mathrm{V}$ viene dada por el tren de artillería de veintiocho carros que tomó seis castillos al enemigo en menos de dos semanas.

La guerra con Castilla de 1429-1430, una guerra «olvidada», marginada por la historiografía dada su escasa relavancia política, se presenta como un excelente laboratorio para el estudio de las estrategias tendentes al incremento de la producción y/o de la productividad susceptibles de ser

${ }^{84}$ Cfr. el excelente artículo de Antonio Malalana Ureña e Itzíar Muñoz Cascante, Mudéjares de la merindad de la Ribera y bailia de Tudela en los ejéritos de Carlos II de Navarra publicado en "Príncipe de Viana», anexo 8 (1988), pp. 525-531. 
puestas en práctica por una sociedad preindustrial como es la Corona de Aragón en el s. xv. Puede constituir la base de un modelo interpretativo original, a partir de la no-centralidad del espacio catalano-aragonés dentro del mercado de la producción de armamento a escala europea. El estudio comparativo de la diferente capacidad de reacción evidenciada por los contendientes, Castilla y la corona catalano-aragonesa, y por los propios territorios integrantes de esta última, sirve para poner de manifiesto tanto sus diferencias estructurales como la jerarquía de sus pesos específicos. Sin lugar a dudas, en 1429-143() Cataluña constituye todavía el centro del potencial económico, político, financiero y productivo de la Corona de Aragón, como demuestran la importancia de la Diputació del General como institución armada y de Barcelona como principal núcleo de producción industrial de retaguardia, capaz de abastecer el frente aragonés allí donde fallan otros centros como Valencia, a la vez que es capaz de exportar un elevado número de personal cualificado hacia el frente para la producción in situ. Una Corona de Aragón que, en su conjunto, muestra una mayor flexibilidad adaptativa frente al reto de la guerra que la Corona de Castilla, cuyo indudablemente mayor potencial de recursos es movilizado de forma lenta y dificultosa frente a la fluidez, celeridad e intensidad que preside el proceso en el lado aragonés.

\section{RÉSUMÉ}

La guerre qui en 1429 et 1430 vit s'affronter les couronnes de Castille et d'Aragon constitue un magnifique banc d'essais pour le chercheur. Parfaitement bien documentée, elle a été paradoxalement négligée par son manque d'impact politique. L'observation point par point des événements permet, cependant, de réaliser une précieuse analyse comparative des caractéristiques et capacités des sociétés en conflit, ainsi que de mieux connaître les stratégies dont disposaient les pouvoirs publics pour se procurer rapidement un armement adéquat et cela dans un contexte pré-industriel caractérisé par l'incapacité dans laquelle étaient les fournisseurs (artisans et commerçants), de couvrir dans de courts délais les brusques augmentations de la demande que provoquait l'éclatement d'une guerre. Comme nous le verrons, pendant que Jeanne d'Arc faisait un sort aux anglais à Orlèans, notre péninsule était le témoin d'événements non moins fascinants.

\section{SUMMARY}

The war that during 1429 and 1430 put face to face the Crowns of Castilla and Aragon, makes a maravellous experimental ground for investigators. Though perfectly well-documented, this fact has been paradoxically negliged because of 
its lack of political impact. If we follow punctually the events, it is nevertheless possible to prepare a valuable comparative analysis of the characteristics and capacities of the societies in conflict. All this is possible thanks to a better knowledge of the strategies of which public powers dispose to manage a rapid and adequat supply of armament, in a preindustrial context caracterised by the incompetence of the suppliers (craftsmen and traders) to cover, within short time limits, sudden increases in the demands of armament derived from outbreaks of wars. As we will see, while Jeanne d'Arc was busy with the English in Orléans, not least impressive events took place in the peninsula. 